\title{
Chemical stability of insulin in a delivery system environment
}

\author{
U.Grau \\ Hoechst Aktiengesellschaft, Frankfurt, FRG
}

\begin{abstract}
Summary. Exposure of insulin solutions to elevated temperatures for prolonged periods of time will inevitably lead to chemical modifications of the hormon. Contact with different materials in dosing devices, other design-related factors and motion appear to be chemically more detrimental than storage in glass vials at the same temperature. An in vitro test, designed to mimick the in vivo situation, consisted of delivery of insulin at $37^{\circ} \mathrm{C}$ while the device was constantly moved on a shaking apparatus. Insulin quality was assessed using high performance liquid chromatography. A polyethylenepoly-
\end{abstract}

propylene glycol-stabilized neutral human insulin solution (HOE $21 \mathrm{PH}$ ) was used. A single insulin derivative is the major modification product which, after passage of the complete infusion system, amounts to up to $10 \%$. The biological potency of the derivative is indistinguishable from native insulin. Delivery of acidic insulin under implant conditions, leads to extensive and multiple insulin derivatization, even though the biological potency remains $95 \%$ after 4 weeks.

Key words: Insulin, insulin stability, insulin delivery systems.
In recent years programmable insulin dosing devices have been developed with the aim of attaining optimal diabetic control [1]. In externally-worn pumps, and even more so in long-term implantable pumps, the insulin is placed in an environment which is hostile to the molecule both physically and chemically. The insulin not only experiences exposure to elevated temperatures, but is also mechanically agitated and held in contact with different materials considered less inert than the conventional glass containers. Finally, it can be exposed to shear and other design-related factors in a peristaltic pump, when it is squeezed through an elastomer and catheter tube.

Physical insulin stability has been widely discussed in the literature [2-6]. In general, the strong tendency of neutral insulin to form insoluble (and sometimes biologically inactive) precipitates necessitates the use of stable insulin preparations in pumps. Stabilization of insulin at neutral $\mathrm{pH}$ can be achieved by the addition of surface active polyethylenepolypropylene glycol (HOE $21 \mathrm{PH})[7,8]$ or by the addition of $80 \%$ glycerol [9]. Acidic insulin is much less prone to denaturation because of increased solubility, and has been used successfully in long-term external Siemens Promedos peristaltic devices [10]. Other stabilization procedures have not yet reached the stage of clinical usage [11], and some others appear to be primarily experimental [4, 12-15].
The lack of chemical stability of $80 \%$ glycerol insulin solutions, by the formation of covalent oligomers and the concomitant loss of biological potency, has been described elsewhere [9]. In this paper the chemical stability of neutral HOE $21 \mathrm{PH}$ and acidic insulin in a pump environment has been investigated in vitro.

\section{Materials and methods}

The acidic insulin preparation used was commercial insulin Hoechst $\mathrm{CS}$ (chromatographed porcine insulin) of $\mathrm{pH} 3.2$, with either 40 or $100 \mathrm{IU} / \mathrm{ml}$. Polyethylenepolypropylene glycol stabilized HOE 21 $\mathrm{PH}$ is a $\mathrm{pH}$ neutral solution of highly purified semisynthetic human insulin [16], containing phenol as a bacteriostatic agent, tris-(hydroxymethyl)aminomethane as buffer and a defined zinc content of $11.1 \mu \mathrm{g} / \mathrm{ml}(\mathrm{U}-40), 28 \mu \mathrm{g} / \mathrm{ml}$ (U-100) or $111 \mu \mathrm{g} / \mathrm{ml}$ (U-400). The surface active stabilizer is always present in a concentration of $10 \mu \mathrm{g} / \mathrm{ml}$. In all experiments, quality controlled ampoules for clinical application were used. The in vitro insulin-pump compatibility test consists of horizontal shaking of the device at continuous $60-80$ cycles per minute with $2-\mathrm{cm}$ displacement at $37^{\circ} \mathrm{C}$, while the insulin is being delivered through the original catheter (moving freely in air) into a steady rubber sealed glass vial held inside the $37^{\circ} \mathrm{C}$ incubation chamber. No loss of water or other constituent of the insulin solution was observed, as all catheters were water- and phenol-impermeable. The insulin was collected over a 1 -week period, after which time it was analyzed and a new glass vial attached to the catheter.

Before the first insulin charge the pumps were run at $37^{\circ} \mathrm{C}$ with constant movement, at rates of about $1 \mathrm{ml} /$ day for at least 3 days with a placebo solution containing all HOE $21 \mathrm{PH}$ constituents except in- 
Table 1. Summary of in vitro insulin delivery experiments (constant movement at $37^{\circ} \mathrm{C}$, see materials and methods

\begin{tabular}{|c|c|c|c|c|c|c|c|c|c|c|c|}
\hline \multicolumn{2}{|l|}{ Pumps } & \multicolumn{2}{|l|}{ Insulin } & \multicolumn{2}{|c|}{ Refill cycles } & \multicolumn{3}{|c|}{ Delivery conditions } & \multicolumn{2}{|c|}{ HPLC analysis } & \multirow{2}{*}{$\begin{array}{l}\begin{array}{l}\text { Biological } \\
\text { potency }\end{array} \\
\begin{array}{l}\text { Number of } \\
\text { samples }\end{array}\end{array}$} \\
\hline & & & $\mathrm{IU} / \mathrm{ml}$ & (weeks) & number & $\mu 1 /$ day & & length $(\mathrm{cm})$ & & number & \\
\hline \multirow[t]{2}{*}{ Device I } & 4 & Neutral & 40 & 10 & 6 & 150 & & 75 & Weekly & 38 & \multirow[t]{2}{*}{2} \\
\hline & 2 & HOE $21 \mathrm{PH}$ & 40 & 10 & 6 & 300 & - & 75 & Weekly & 18 & \\
\hline \multirow[t]{2}{*}{ Device II } & 2 & Neutral & 100 & 7 & 2 & 48 & - & 50 & Weekly & 24 & - \\
\hline & 2 & $\begin{array}{l}\text { Acidic } \\
\text { Hoechst CS }\end{array}$ & 100 & 4 & 2 & 240 & - & 50 & Weekly & 14 & 8 \\
\hline \multirow{2}{*}{ Device III } & 2 & Neutral & 100 & 4 & 12 & 280 & - & 20 & Weekly & 72 & 4 \\
\hline & 1 & HOE $21 \mathrm{PH}$ & 400 & 7 & 2 & 70 & - & 20 & Weekly & 17 & - \\
\hline Device IV & 4 & $\begin{array}{l}\text { Neutral } \\
\text { HOE } 21 \mathrm{PH}\end{array}$ & 40 & 4 & 6 & 290 & - & 20 & Weekly & 29 & - \\
\hline Device V & 4 & HOE $21 \mathrm{PH}$ & 100 & 4 & 20 & $1150-1500$ & - & 50 & Weekly & 120 & 4 \\
\hline
\end{tabular}
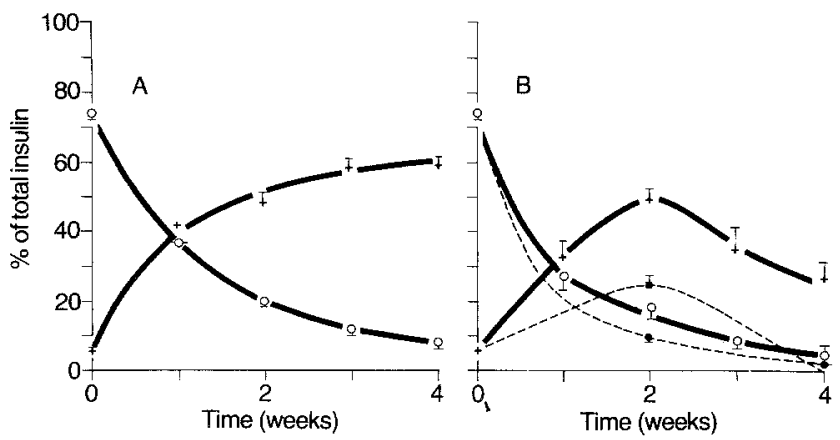

Fig. 1 A and B. Kinetics of desamido (A21) insulin formation $(+-+)$ and native insulin disappearance $(\mathrm{O}-\mathrm{O})$ from an acidic insulin preparation inside $\mathbf{A}$ a steady glass vial at $37^{\circ} \mathrm{C}$ and $\mathbf{B}$ when delivered through a pump in motion at $37^{\circ} \mathrm{C}$. The dashed line represents native insulin (--) and desamido (A21) insulin ( $-\mathbf{0})$ in samples taken from the dead space near the refill septum during the same experiment. Bars indicate standard deviations

sulin. This procedure was designed to saturate surfaces with the surface-active stabilizer. The presence of the stabilizer in the subsequent HOE $21 \mathrm{PH}$ refill was checked by measuring the surface tension of the solution using a Krüss tensiometer (Pt-ring method). During the saturation procedure which will have to be performed once before implantation by the manufacturer, no leaching chemicals were seen in HPLC analysis.

Among the insulin pumps used in the test were the Siemens Promedos E 1 (external) [17] and Promedos I 1 (implantable) [18, 19], the Medtronic implantable drug administration device [18], the Pacesetter implantable medication system [18], and the Infusaid constant basal rate device $[18,20]$. In each case, the original catheter supplied by the pump manufacturer was used, since it must be considered an integral part of the system. The catheters differed in length, but their volume, i. e. the overall residence time of the insulin was similar. In each case, the same catheter was used throughout the study. Experimental details are summarized in Table 1.

A reference sample of the insulin solution was held steady in its original glass container in the $37^{\circ} \mathrm{C}$ incubation chamber. Duplicate samples of two individual batches were analyzed.

Insulin quality has been assessed using reversed-phase high performance liquid chromatography (RP-HPLC) on a Waters System consisting of a model M45 and model 6000 A pump, a model 721 controller, a model M730 data module, a model 710B automatic sample injector and a model 481 optical detector. The column was a Waters $5 \mu \mathrm{C} 18$ Radial Pak compressed inside a $\mathrm{Z}$ module, operated at ambient temperature. The mobile phase consisted of a linear gradient of $28 \% \mathrm{~B}$ to $40 \% \mathrm{~B}$, where solvent A contains $50 \mathrm{mM}$ tetraethylammoniumphosphate, $0.25 \mathrm{M}$ sodium perchlorate and $10 \%$ acetonitrile, $\mathrm{pH}=3.0$, and solvent $\mathrm{B}$ contains $50 \mathrm{mM}$ tetraethylammonium phosphate, $90 \%$ acetonitrile, $\mathrm{pH}=3.0$. This solvent system has been optimized for insulin analysis (G. Sepke, unpublished data) and is similar to the one used by Shoelsen et al. [21]. Generally, the samples were stored at $4{ }^{\circ} \mathrm{C}$ in the glass vial for no longer than 2 weeks before analysis. A $20-\mu 1$ aliquot of the original insulin solution, without any further manipulation, was injected and detection was at $210 \mathrm{~nm}$ (note that the corresponding chromatograms are heavily overloaded in order to detect small amounts of derivatives). The present data set (Table 1) did not contain solutions showing any turbidity on visual inspection.

Insulin quantity was determined with reference to an external standard. The total peak area of the HPLC run of a given sample (with the exception of the phenol or p-hydroxybenzoic acid methyl ester peaks), was divided by the total peak area of an equally concentrated aqueous insulin standard (identical injection volumes, analysis on the same day) and calculated as a percentage thereof.

The total peak area of the sample HPLC run (with the exception of the preservative peak) was then set to correspond to $100 \%$, and each individual peak was calculated as a percentage thereof. Routinely, a reference mix of human insulin, bovine insulin, desoctapeptideinsulin, porcine proinsulin and desamido (A21) or desamido (B3) human insulin [22] was analyzed.

The precision of the described HPLC insulin quantification method, based on repeated 10 consecutive injections of reference samples, is better than $\pm 5 \%$. High-purity acetonitrile for HPLC analysis was purchased from Promochem; all the other chemicals were from Merck, A. R. quality.

The pump-generated insulin derivative was isolated from enriched samples (e.g. recycled inside the same device) using preparative HPLC on a Vydac TP RP $10 \mu$ particle size column of $25 \mathrm{~cm} \times 4.6 \mathrm{~mm}$ (inner diameter) dimensions. The solvent system was a n-butanol/ethanol/water mixture [23].

The Staphylococcus aureus protease V8 fingerprint was performed in $0.2 \mathrm{M}$ Tris $/ \mathrm{HCl}, \mathrm{pH}=7.3$, at $37^{\circ} \mathrm{C}$ for $2 \mathrm{~h} .0 .1 \mathrm{U}$ of the enzyme (Sigma) was incubated with $200 \mu \mathrm{g}$ of the insulin derivative in $220 \mu \mathrm{l}$ buffer. The analysis of peptide fragments was performed using the HPLC system described above, except that the gradient was run from $20 \%$ to $45 \%$ solvent $B$. 


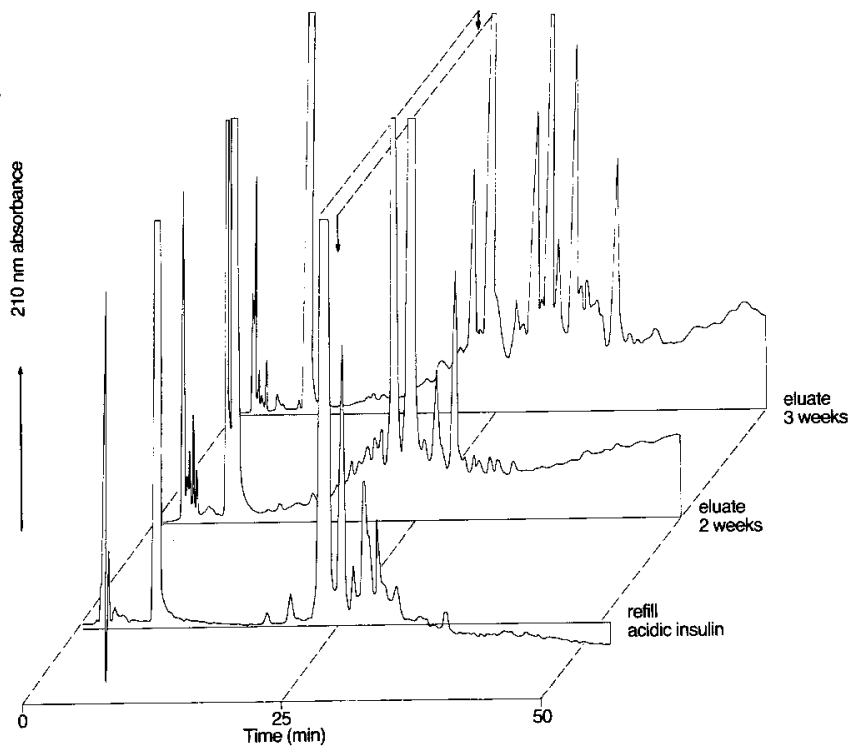

Fig.2. Reversed-phase high-performance liquid chromatography (HPLC) diagrams of acidic porcine insulin at refill and off the catheter tip of dosing device II (Table 1) after 2 and 3 weeks' bench test at $37^{\circ} \mathrm{C}$, respectively. The initial increase of desamido (A21) insulin (eluting at $25 \mathrm{~min}$ ) and subsequent decrease is pointed out by the dashed line, as is the steady decrease of unmodified native insulin (eluting at $23.5 \mathrm{~min}$ ) peaks near the front represent salts and methylparaben. Absorbance was measured at $210 \mathrm{~nm}$

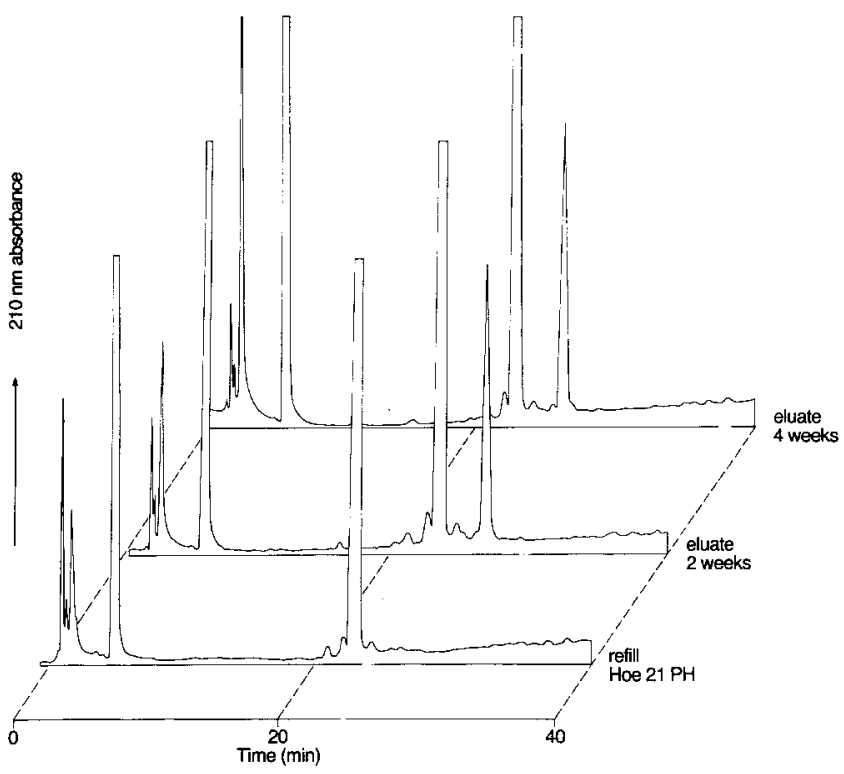

Fig. 3. HPLC diagrams of neutral human insulin HOE $21 \mathrm{PH}$ at refill and, after 2 or 4 weeks' bench test at $37^{\circ} \mathrm{C}$, off the catheter tip, delivered through dosing device II

Biological potency of insulin solutions was in each case determined in 24 rabbits with 2 doses according to the Pharmacopoeia standard procedure [24]. The precision of the assays which were performed in a routine quality control laboratory was calculated individually for each sample; it is typically $\pm 10 \%$.

\section{Results}

As described earlier by several investigators [25-27], insulin in acidic solution undergoes rapid deamidation at elevated temperature. At $37^{\circ} \mathrm{C}$ in a steady glass vial, the content of unmodified insulin dropped within 4 weeks to about $10 \%$, while the monodesamido (A21) insulin increased to about $60 \%$ (Fig. 1). When pumped through a dosing device kept in motion at $37^{\circ} \mathrm{C}$, the kinetics of this deamidation process were initially similar, but from week 2 on, the content of either native insulin or monodesamidoinsulin decreased (Fig. 1), while several new species were formed eluting past insulin from the reversed-phase column in HPLC analysis (Fig. 2).

After 4 weeks of residence at $37^{\circ} \mathrm{C}$ inside the two dosing devices in the test, and after delivery, the total insulin quantity eluting from the HPLC column was only 60 or $64 \%$ of the original value, suggesting that some derivatives are being adsorbed onto the reversed-phase material. No turbidity was detected upon visual inspection. The biological potency of the pump eluate and pump reservoir contents after 3 and 4 weeks, and of the reference samples incubated at $37^{\circ} \mathrm{C}$ for 4 weeks, were all better than $92 \%$ (average $95 \%$ ) of the original $100 \mathrm{IU} / \mathrm{ml}$ value.

Delivery of neutral HOE $21 \mathrm{PH}$ through the same system at identical conditions revealed a much more straightforward HPLC pattern. The content of native insulin dropped by about $10 \%$ during the 4 -week refill cycle, this same amount being largely made up by a single insulin derivative eluting from the HPLC column at about 26 min in the gradient (Fig. 3).

Within the 4-week refill cycle, neither desamido (A21) insulin nor desamido (B3) insulin increased significantly.

The formation of the modified insulin species generated in dosing devices reached an apparent steady state (Fig.4) when the eluate was collected in a glass vial, which was attached to the catheter for 1 week, and remained at $37^{\circ} \mathrm{C}$ during this time. Corresponding samples from the reservoir did show a lower content of the derivative, ranging up to about $2 \%$ only.

Delivery of subsequent $10 \mathrm{U}$ boli $(100 \mu \mathrm{l}$ each $)$ (Fig. 5) showed that about 5\% of the derivative were formed in the collecting vial. In the first aliquot, $4.2 \%$ content of the derivative was found, but its proportion decreased to the $2.1 \%$ value obtained for the reservoir sample (dashed line in Fig.5). The volume of pump tube and catheter in this particular device is very nearly 500 ul.

In a control experiment, the neutral insulin preparation HOE $21 \mathrm{PH}$ was incubated at $37^{\circ} \mathrm{C}$ in a glass vial without movement. Within 4 weeks, the insulin derivative characterized by elution from the reversed-phase column at 26 minutes was present in $1.2 \%$ quantity. Hence, the passage through the dosing system leads to an exaggeration of the artificial effect due to the sample collection mode. 

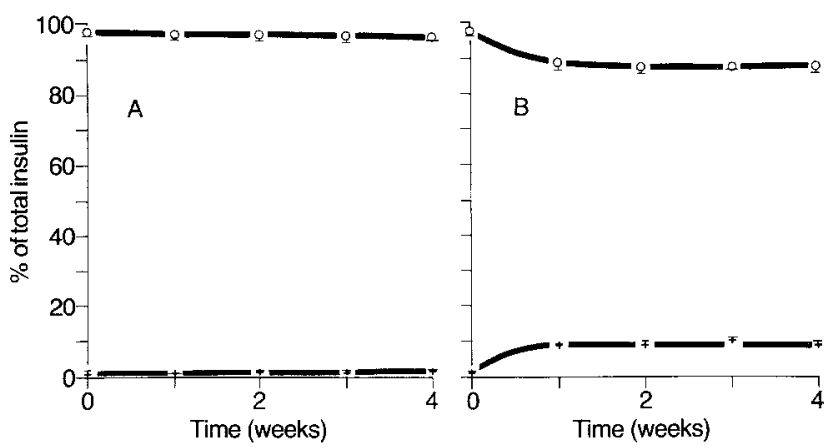

Fig. 4 $\mathrm{A}$ and B. Kinetics of formation of the insulin derivative eluting at 26 min in HPLC analysis $(+-+)$ and concommitant decrease of native human insulin (O-O) in $\mathbf{A}$ a steady glass vial at $37^{\circ} \mathrm{C}$ and $\mathbf{B}$ when pumped by a dosing device in motion at $37^{\circ} \mathrm{C}$. Bars indicate standard deviations

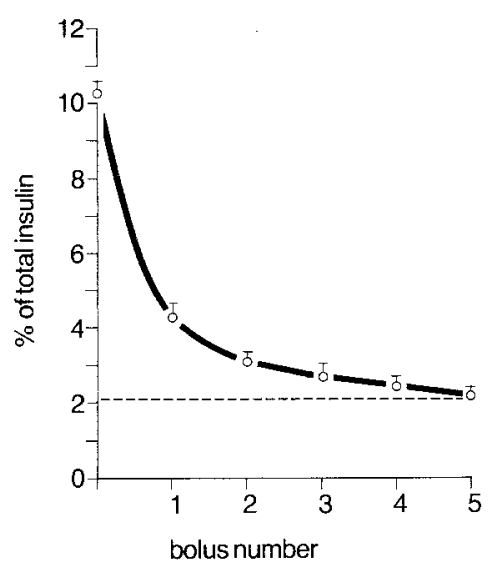

Fig.5. Tracing of the relative amount of the insulin derivative eluting at $26 \mathrm{~min}$ in HPLC analysis along the drug pathway by subsequent delivery of $10 \mathrm{IU}(100 \mu \mathrm{l})$ boli. The dashed line represents the proportion of the derivative inside the reservoir. This experiment was performed at the end of a 4-week refill cycle. Bars indicate standard deviations

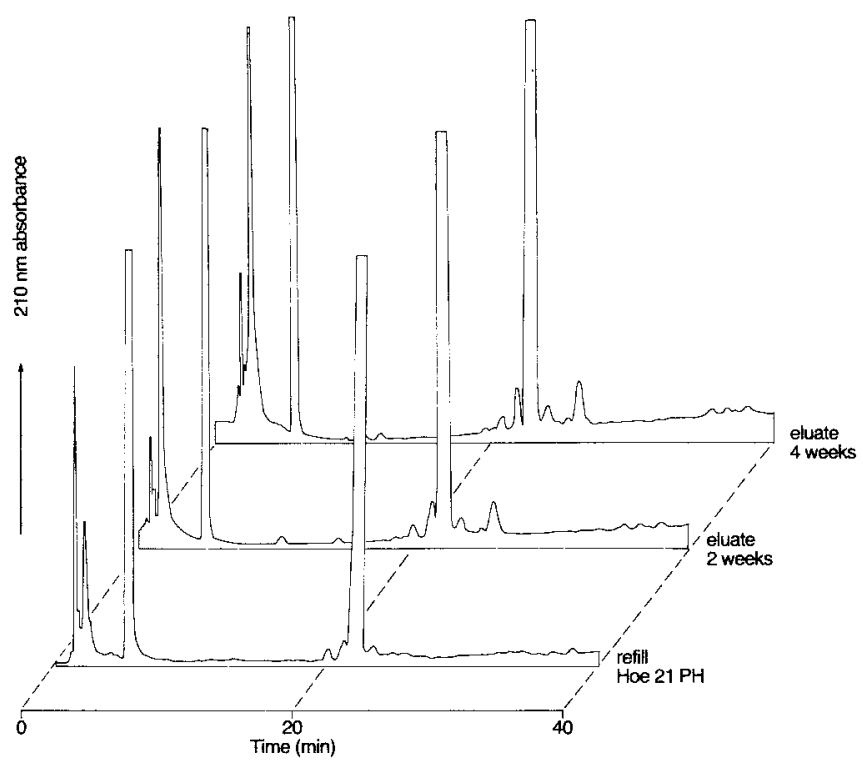

Fig. 6. HPLC diagrams of neutral human insulin HOE $21 \mathrm{PH}$ at refill and, after 2 or 4 weeks' bench test at $37^{\circ} \mathrm{C}$, off the catheter tip, delivered through dosing device III
In a different dosing device (device III, Table 1) operating under almost identical conditions, the proportion of the described HOE 21 PH derived insulin derivative was substantially lower (Fig. 6). In fact, native insulin remained at better than $95 \%$ over the full 4 weeks of the refill cycle. It is to be noted, that in this case a shorter catheter was part of the authentic system, even though the volume, i.e. the insulin residence time, was very similar.

In a third implantable pump, the proportion of the insulin derivative eluting at $26 \mathrm{~min}$ from the HPLC column was typically about $3 \%$ and, in a fourth device it was about $10 \%$. Finally, in a fifth device running, however, on a higher rate, the derivative reached about $5 \%$. In either case with neutral HOE $21 \mathrm{PH}$, the HPLC chromatograms were very similar to those shown in Figures 3 and 6 and an apparent steady state (compare to Fig. 4 ) was reached at the $3 \%, 10 \%$ and $5 \%$ level, respectively.

With HOE 21 PH (a total of 381 analyses), the sum of the eluted insulin peak areas (total peak area in the HPLC chromatogram with the exception of the phenol peak) was very similar to the standard. Likewise, biological potency was always indistinguishable from the reference solution (refer to Table 1 for more details of the data set).

A sample of $\mathrm{HOE} 21 \mathrm{PH}$, which was recycled inside a pump to generate $74 \%$ of the derivative characterized by elution from the HPLC column at $26 \mathrm{~min}$, did show a potency of $98 \%$ of the reference insulin in the biological assay.

\section{Discussion}

The recent widespread usage of highly purified insulins which was made possible by the advent of highly efficient separation and sensitive protein analytical methods, has had an unpredictable but profound impact on the pump therapy field. Insulin is most physically stable where it is also least chemically stable and vice versa. Insulin-related catheter occlusion problems are rare events when an acidic insulin solution is infused by a dosing device [10] while this seems to occur quite frequently and in a much shorter time with neutral conventional insulin solutions.

In acidic solution, insulin undergoes rapid deamidation, most prominently at asparagine A21, with formation of the free carboxylic acid $[26,27]$. The deamidation process is rapid at body temperature and monodesamidoinsulin is formed; however this is not inferior to the native insulin, either biologically or immunologically $[28,29]$.

In the implantable pump environment, the modification pattern gets more complicated. In particular, monodesamido (A21) insulin, which is found in HPLC analysis to elute just past the native insulin, is not the major modification product within the time frame rele- 
vant for dosing devices. At its expense, several new species turn up (Fig. 2). Chemical modification, in particular deamidation, can take place at several of the six asparagines or glutamines within the human insulin sequence [26]. It appears plausible, therefore, that such a mixture of multiply modified insulin may have been generated. Furthermore, soluble covalent insulin oligomers or desamidated insulin oligomers formed by transamidation reactions appear possible by-products, some of which may be bound irreversilby to the RP-column and account for the observed loss. The recovery of monomeric and dimeric insulins from the RP column, as, for instance, in all HOE $21 \mathrm{PH}$ samples analyzed here, is very nearly ideal. The biological potency of eluate and reservoir samples from the bench test after 3 or 4 weeks was determined to be $>92 \%$ of the original value.

Conventional neutral insulin solutions are highly sensitive to denaturation in dosing devices; by the addition of a surface-active polyethylenepolypropylene glycol-type stabilizer and by careful optimization of the other constituents such as the zinc content, a remarkable increase in physical stability has been achieved [7, 8]. The stabilizer is completely inert and is present in trace quantities only.

With respect to chemical stability, neutral insulin preparations, in general, are preferable [22, 30]. Delivery of neutral HOE $21 \mathrm{PH}$ through a dosing device leads to the formation of one specific derivative eluting past insulin at about $26 \mathrm{~min}$ in the gradient, which is almost undetectable upon storage in a glass vial (Figs. 2 and 3). (The chromatograms of Figures 2 and 3 have been obtained from samples from the same device.)

The proportion of the derivative varies from one device to another; thus, the environment (materials, diffusion phenomena etc.) influences not only the physical, but also the chemical insulin stability.

In a clinical environment, the insulin is being distributed immediately from the catheter tip; the in vitro test system, which, for practicability reasons, consisted of collection of the eluate over a 1-week period, is clearly more strenuous on the insulin and produces some artifacts. The experiment in which five subsequent boli were delivered, indicates, that under normal operation in vivo, up to about $5 \%$ of the insulin may get modified before the hormone reaches the body. Thus, the chemical stability of the neutral preparation HOE $21 \mathrm{PH}$ inside the five dosing devices tested is almost as good as the $37^{\circ} \mathrm{C}$ reference sample.

What is the chemical nature of the derivative? Using the $\mathrm{S}$. aureus fingerprint technique, it could be demonstrated that the modification is located in the N-terminal region of the B-chain and that no covalent crosslinks between molecules are present. Further work, however, will be needed to reveal the exact chemical constitution and the mechanisms of formation of this modified insulin. The pump-generated derivative possesses full biological potency. Furthermore, it does not lead to increased insulin antibody formation in pigs compared to native human insulin (H.P. Neubauer, personal communication).

In conclusion, unlike acidic insulin, the neutral insulin preparation HOE $21 \mathrm{PH}$ reaches the body in practically the same high quality as the original insulin which was charged into the pump reservoir. If, in addition, the physical insulin stability in a given device can be established in vitro and in animal experiments, then pump therapy with long-term reservoirs as in implants can - from an insulin point of view - be considered safe for further clinical evaluation.

Acknowledgements. I wish to express thanks to Dr. H.H.Schöne for helpful discussions. The collaboration with engineers, physicists and material scientists has also been mutually rewarding. In particular, I should like to mention Drs. D. Elsberry, R.E. Fischell, M.Franetzki, P.Jährling, P. Lord, K. Prestele, and G. Taylor. Finally, I am grateful to W. Schäfer, T. Buric, and W. Kilian for their technical assistance, and to R. Lohfink for the preparation of this manuscript.

\section{References}

1. Irsigler K, Kritz H, Lovett R (eds) (1983) Diabetes treatment with implantable insulin infusion systems. Urban \& Schwarzenberg, Munich Vienna Baltimore

2. Irsigler K, Kritz H (1979) Long-term continuous intravenous insulin therapy with a portable insulin dosage-regulating apparatus. Diabetes 28: 196-203

3. Thurow H (1980) Studies on the denaturation of dissolved insulin. In: Brandenburg D, Wollmer A (eds) Insulin chemistry, structure and function of insulin and related hormones. de Gruyter, Berlin New York, pp 215-221

4. Lougheed WD, Woulfe-Flanagan H, Clement JR, Albisser AM (1980) Insulin aggregation in artificial delivery systems. Diabetologia 19:1-9

5. Lougheed WD, Albisser AM, Martindale HM, Chow JC, Clement JR (1983) Physical stability of insulin formulations. Diabetes 32: 424-432

6. Blackshear PJ, Rohde TD (1982) Artificial devices for insulin infusion in the treatment of patients with diabetes mellitus. In: Bruck SD (ed) Controlled drug delivery, Vol II. Clinical applications. CRC press, Boca Raton, pp 111-147

7. Grau U (1985) Insulin stability. In: Hepp KD, Renner R (eds) Continuous insulin infusion therapy. Experience from one decade. Schattauer, Stuttgart New York, pp 33-46

8. Thurow H, Geisen K (1984) Stabilisation of dissolved proteins against denaturation at hydrophobic interfaces. Diabetologia 27: 212-218

9. Blackshear PJ, Rohde TD, Palmer JL, Wigness SD, Rupp WM, Buchwald H (1983) Glycerol prevents insulin precipitations and interruption of flow in an implantable insulin infusion pump. Diabetes Care 6: 387-392

10. Selam JL, Giraud P, Mirouze J, Saeidi S, Hedon B, Slingeneyer A, Lapinski H, Humeau C (1985) Continuous peritoneal insulin infusion with portable pumps: factors affecting the operating life of the chronic catheter. Diabetes Care $8: 34-38$

11. Pongor S, Brownlee M, Cerami A (1983) Preparation of high-potency, non-aggregating insulins using a novel sulfation procedure. Diabetes 32: 1087-1091

12. Albisser AM, Lougheed W, Perlman K, Bahoric A (1980) Nonaggregating insulin solutions for long-term glucose control in experimental and human diabetes. Diabetes 29:241-243

13. Bringer J, Heldt A, Grodsky GM (1981) Prevention of insulin aggregation by dicarboxylic amino acids during prolonged infusion. Diabetes 30: 83-85 
14. Brange J, Havelund S (1983) Insulin pumps and insulin quality-requirements and problems. Acta Med Scand (Suppl) 671:135-138

15. Sato S, Ebert CD, Kim SW (1983) Prevention of insulin self-association and surface adsorption. J Pharm Sci 72: 228-232

16. Obermeier R, Seipke G (1984) Enzyme-catalyzed semisyntheses with porcine insulin. Process Biochemistry 19:29-32

17. Prestele K, Franetzki M, Kresse H (1980) Development of program-controlled portable insulin delivery devices. Diabetes Care 3: $362-368$

18. Taylor G, Lebisch H, Weinmann P, Champion JR (1983) Devices and materials. Reports from representatives of industry. In: Irsigler K, Kritz H, Lovett R (eds) Diabetes treatment with implantable insulin infusion systems. Urban \& Schwarzenberg, Munich Vienna Baltimore, pp 29-39

19. Irsigler K, Kritz H, Hagmüller G, Franetzki M, Prestele K, Thurow H, Geisen K (1981) Long-term continuous intraperitoneal insulin infusion with an implanted remote-controlled insulin infusion device. Diabetes 30: 1072-1075

20. Blackshear PJ, Dorman FD, Blackshear PL jr., Varco RL, Buchwald $H$ (1972) The design and initial testing of an implantable infusion pump. Surg Gynecol Obstet 134: 540-543

21. Shoelson S, Haneda M, Blix P, Nanjo A, Sanke T, Inouye K, Steiner D (1983) Three mutant insulins in man. Nature 302: $540-543$

22. Brange J, Langkjaer L, Havelund S, Sørensen E (1983) Chemical stability of insulin: neutral insulin solutions. Diabetologia 25:143 (Abstract)

23. Luiken J, Van der Zee R, Welling GW (1984) Structure and activity of proteins after reversed-phase high-performance liquid chromatography. J Chrom 284: 482-486
24. European Pharmacopoeia (1975) Assay of insulin (method A) by subcutaneous injection into rabbits, Vol III. Maisonneuve S.A., Sainte Ruffine, $\mathrm{p} 75$

25. Harfenist EJ, Craig LC (1952) Countercurrent distribution studies with insulin. J Am Chem Soc 74: 3883-3088

26. Carpenter FH, Crambach A (1962) On the amide content of insulin fractions isolated by partition column chromatography and countercurrent distribution. J Biol Chem 237: 404-410

27. Sundby F (1962) Separation and characterization of acid-induced insulin transformation products by paper electrophoresis in $7 \mathrm{M}$ Urea. J Biol Chem 237:3406-3412

28. Kurtz AB, Nabarro JDN (1980) Circulating insulinbinding antibodies. Diabetologia 19:329-334

29. Kasama T, Iwata Y, Oshiro K, Uchida M, Sakaguchi S, Namic K, Sagiura M (1981) Antigenicity of desamido-insulin and monocomponent insulin. Diabetologia 21: 65-69

30. Pingel M, Vølund A (1972) Stability of insulin preparations. Diabetes $21: 805-813$

Received: 28 September 1984

and in revised form: 13 May 1985

Dr. U. Grau

Pharma Forschung

Biochemie I H 825

Hoechst AG

Postfach 800320

D-6230 Frankfurt am Main 80 